\title{
Motorized 2-3 wheelers death rates over a decade: a global study
}

\author{
Yasin J. Yasin ${ }^{1,2}$, Michal Grivna ${ }^{1,3}$ and Fikri M. Abu-Zidan ${ }^{4 *}$
}

\begin{abstract}
Background: Motorized 2-3-wheelers-related death is high due to the exposed body of the driver/passenger and the high speed. The United Nation (UN) Decade of Action for road safety aimed to reduce road traffic deaths by $50 \%$ by the year 2020. We aimed to study the factors affecting the death rates of motorized $2-3$ wheelers injured victims and whether the reduction in the death rates has met the UN target.

Methods: Data were retrieved from the WHO Global Status Reports on Road Safety published over 2009 to 2018 which covered the years of 2007 to 2016. Studied variables included motorized 2-3 wheelers death rates, percentage of helmet-wearing rate, helmet law enforcement, speed law enforcement, gross national income per capita, vehicles/ person ratio, and motorized 2-3 wheelers/person ratio. A mixed linear model was used to define factors affecting the change of motorized 2-3 wheelers death rates over time.

Results: The global mean motorized $2-3$ wheelers death rates increased from 2.37/100,000 population to $3.23 / 100,000$ population over the studied decade (a relative ratio of 1.36 ) which was not statistically significant. Factors that affected mortality included GNI $(p=0.025)$, motorized $2-3$ wheelers per person ratio $(p<0.0001)$, percentage of helmet wearing rate $(p=0.046)$, and the interaction between vehicle/person ratio and motorized $2-3$ wheelers/ person ratio $(p=0.016)$. There was a significant increase in the death rates over time in the low-income countries (a relative ratio of $2.52, p=0.019$, Friedman test), and middle-income countries (a relative ratio of 1.46, $p<0.0001$, Friedman test), compared with a significant decrease in the high-income countries (a relative ratio of $0.72, p<0.0001$, Friedman test).

Conclusions: Global mortality of motorized $2-3$ wheelers has increased by a relative ratio of 1.36 over a recent decade. The UN target of reducing death was not met. The increase was related to the increase in motorized 2-3 wheelers per person ratio and economic inequity which has to be addressed globally. The economic global gap significantly impacts the mortality rates of motorized $2-3$ wheelers.
\end{abstract}

Keywords: Global, 2-3 Wheelers, Motorcycle, Death, Road traffic collision, Road safety

\section{Introduction}

Over the last decade, more than 13 million people died from road traffic collisions (RTCs) [1]. Around 2 billion vehicles are used globally of which $30 \%$ are motorized 2-3 wheelers [1-3]. Low- and middle-income countries

*Correspondence: fabuzidan@uaeu.ac.ae

${ }^{4}$ Department of Surgery, College of Medicine and Health Sciences, UAE University, Al-Ain, United Arab Emirates

Full list of author information is available at the end of the article
(LMICs) use $88 \%$ of these wheelers of which $75 \%$ are in Southeast Asia [3]. There is a rapid increase in the use of motorized 2-3 wheelers worldwide because of their availability, flexibility, and affordability with the highest growth rate is in Southeast Asia (39\%) [3-6]. Riding a motorized 2-3 wheeler is very risky because of the high speed and the exposed bodies of the driver and passenger. The risk of death from a crash is 28 to 34 times higher than for a car occupant $[7,8]$. A quarter of road traffic deaths involve motorized 2-3 wheelers, with 
approximately 3.2 million deaths over the past decade [1, $3,9,10]$.

In response to this growing burden, the United Nations (UN) approved a Global Plan for the Decade of Action for Road Safety 2011-2020 aiming to reduce road deaths by half in 2020 [11]. Continuous evaluation of the global changes is essential to find whether the action plan is properly progressing [12]. The World Health Organization (WHO) Global Status Reports on Road Safety plays an important role in this evaluation $[1,9,10,13]$. Although previous studies have examined the factors affecting the global motorized 2-3-wheeler-related deaths, they neither used repeated time global data nor examined the factors affecting the change over time [14]. Thus, we aimed to study the factors affecting the death rates of motorized 2-3 wheeler injured victims over time and whether the reduction in death rates has met the UN target.

\section{Methods}

\section{Ethical consideration}

Data used in this study are publicly available data from the WHO Global Status Report on Road Safety and do not need approval from a Human Research Ethics Committee.

\section{Definition of 2-3 wheelers}

Motorized 2-3 wheelers refers to powered two- and three wheelers [3]. According to the WHO definition, "motorized 2-3 wheelers or powered two- and three wheelers (PTWs) are motor-operated two- and threewheeled vehicles, powered by either a combustion engine or rechargeable batteries." These included motorcycles, scooters, e-bikes, tricycles motor-rickshaws, or e-rickshaws [3].

\section{Data collection}

Data were retrieved from the WHO Global Status Reports on Road Safety for years 2007, 2010, 2013, and 2016 , which were published in 2009, 2013, 2015, and 2018 , respectively $[1,9,10,13]$. These reports had data on $178,182,180$, and 175 countries, respectively, with complete data on motorized 2-3 wheelers death on 115 (64.6\%), 123 (67.6\%), 117 (65.0\%), and 122 (69.7\%) countries, respectively. The area of countries was retrieved from the infoplease.com website [15].

\section{Studied variables}

Studied variables included the percentage of estimated helmet-wearing rate, the effectiveness of helmet law enforcement, the effectiveness of speed law enforcement, estimated road traffic deaths rate per 100,000 population, percentage of motorized 2-3 wheelers death, country population, gross national income (GNI) per capita in US dollars, number of registered vehicles, and percentage of motorized 2-3 wheelers in each country.

The percentage of motorized 2-3 wheelers death included all riders (drivers or passengers). The percentage of estimated helmet-wearing rate in our study included all riders. However, if data was not available on all riders, we used instead the reported percentage of estimated helmet-wearing rate of drivers. Information on the overall effectiveness levels of both helmet law enforcement and speed limit enforcement were scored on a scale of 0 to 10 , where 0 is "not effective" and 10 is "highly effective" based on professional consensus in each country.

\section{Data entry}

Data collected during all studied years were coded and entered into the MS Excel program in two formats: vertical data format (the same variables in all studied years were entered into a single column in order of years with an added year variable), and horizontal data format (each variable in each studied year entered into a separate column). Data were rechecked for accuracy and consistency and exported into SPSS for analysis.

\section{Calculations}

The population density was calculated by dividing the total population by country area (number of people/ mile square). The number of motorized $2-3$ wheelers was calculated by multiplying the percentage of motorized 2-3 wheelers by the total number of registered vehicles. Motorized 2-3 wheelers death rate was calculated by multiplying the percentage of motorized 2-3 wheelers death by the estimated traffic road death rates per 100,000 population. Vehicle per person ratio was calculated by dividing the total number of registered vehicles by the total population. Motorized 2-3 wheelers per person ratio was calculated by dividing the total number of motorized 2-3 wheelers by total population.

\section{Statistical analysis}

Mortality rates were highly skewed to the right. Accordingly, median (interquartile range, IQR) were used in reporting the data. We used a mixed linear model (MLM) to assess the factors affecting motorized 2-3 wheelers death rates over time. Death rates were transformed to a normal distribution to fulfill the requirements of the MLM. Log transformation had the best normal distribution over time and within each year and was used as the outcome variable.

The MLM analyses data of repeated measures (years) of each country (subject) separately, taking into account both the slope and intercept of each linear line of a country (within-subjects correlation). Studying the slope has 
an important advantage of addressing missing data and the nonlinear relationship between different factors. MLM assumes a normal distribution of the outcome (dependent) variable. The logarithmic transformation of death rate was the dependent variable of the MLM model, while independent covariates do not need to have a normal distribution which can be ordinal, continuous, or categorical data.

The used MLM model was a strict unstructured, maineffects model with repeated measures. It included a fixed effect, type III sum of squares error (due to the unbalanced data), and random effects for the independent variables (factors and covariates). These strict requirements assume that the variance of each studied year and the covariance (correlation) between the studied independent factors are different. The change of the outcome-dependent variable (death rate) was studied over time by entering the studied years as a categorical factor (factor $=$ year) while independent variables as covariates. These included continuous variables (population density, GNI per capita, vehicle per person ratio, and motorized 2-3 wheelers per person ratio) and ordinal variables (speed law enforcement (0-10) and helmet law enforcement $(0-10))$. We tested different interactions in the model, excluded non-significant and included significant interactions in the final MLM model. Accordingly, the interaction between vehicle per person ratio and motorized 2-3 wheelers per person ratio was added to the final main effects model.

After achieving the results of the final MLM model, several univariate post hoc analyses were performed to explain our findings. Spearman rank correlation test was used to study the correlation between different continuous or ordinal variables. Wilcoxon signed-rank test was used to compare the continuous or ordinal data of two dependent groups. Friedman test was used to compare the continuous or ordinal data of more than two dependent groups. Mann-Whitney U test was used to compare the continuous or ordinal data of two independent groups, while Kruskal-Wallis test was used to compare the continuous or ordinal data of more than two independent groups. Data were analyzed with the IBM SPSS Statistics version 26 (SPSS Inc, Chicago, IL, USA). A $p$-value of less than 0.05 was accepted as statistically significant.

\section{Results}

Table 1 shows the results of the mixed linear model. The model showed factors that affected the log transformation of motorized $2-3$ wheelers death rates. The significant factors were GNI $(p=0.025)$, motorized $2-3$ wheelers per person ratio $(p<0.0001)$, percentage of helmet wearing rate $(p=0.046)$, and the interaction between vehicle per person ratio and motorized $2-3$ wheelers per person ratio $(p=0.016)$. No significant differences in mortality were seen over time. This was confirmed using post hoc analysis ( $p=0.38$, Friedman test) (Fig. 1). Although non-significant, the global mean motorized 2-3 wheelers death rates increased from $2.37 / 100,000$ population to $3.23 / 100,000$ population over the studied decade (a relative ratio of 1.36).

Nevertheless, there was a significant difference in the death rates depending on the income level. There was a statistically significant increase in mortality rate in low-income countries over time $(p=019$, Friedman test, Fig. 2A). The mean death rate in the low-income

Table 1 Linear mixed effect model of factors affecting log transformation of motorized 2-3 wheelers death rate globally over 20072016

\begin{tabular}{|c|c|c|c|c|c|c|}
\hline Variable & Estimate & SE & $t$-value & $p$-value & LL $95 \% \mathrm{Cl}$ & UL $95 \% \mathrm{C}$ \\
\hline Year 2007 & 0.017 & 0.130 & 0.133 & 0.896 & -0.266 & 0.301 \\
\hline Year 2010 & 0.059 & 0.100 & 0.591 & 0.558 & -0.144 & 0.262 \\
\hline Year 2013 & -0.003 & 0.083 & -0.041 & 0.968 & -0.170 & 0.163 \\
\hline Density of population & $5.779^{-5}$ & $5.536^{-5}$ & 1.044 & 0.302 & $-5.370^{-5}$ & $0.169^{-3}$ \\
\hline GNI & $-1.220^{-5}$ & $5.239^{-6}$ & -2.329 & 0.025 & $-2.280^{-5}$ & $-1.602^{-6}$ \\
\hline Vehicle per person ratio & 0.545 & 0.489 & 1.114 & 0.268 & -0.427 & 1.517 \\
\hline Motorized 2-3 wheelers/person ratio & 7.851 & 1.725 & 4.552 & 0.000 & 4.433 & 11.270 \\
\hline Enforcement of speed & -0.039 & 0.023 & -1.666 & 0.103 & -0.087 & 0.008 \\
\hline Enforcement of helmet & 0.011 & 0.021 & 0.531 & 0.599 & -0.031 & 0.053 \\
\hline Percentage of helmet wearing rate & -0.004 & 0.002 & -2.047 & 0.046 & -0.008 & $-7.898^{-5}$ \\
\hline $\begin{array}{l}\text { Vehicle/person ratio * motorized 2-3 wheel- } \\
\text { ers/person ratio }\end{array}$ & -4.792 & 1.953 & -2.454 & 0.016 & -8.667 & -0.916 \\
\hline Intercept & 0.637 & 0.249 & 2.558 & 0.012 & 0.143 & 1.131 \\
\hline
\end{tabular}

$\mathrm{SE}$, standard error; LL, lower limit; $\mathrm{Cl}$, confidence interval; UL, upper limit 


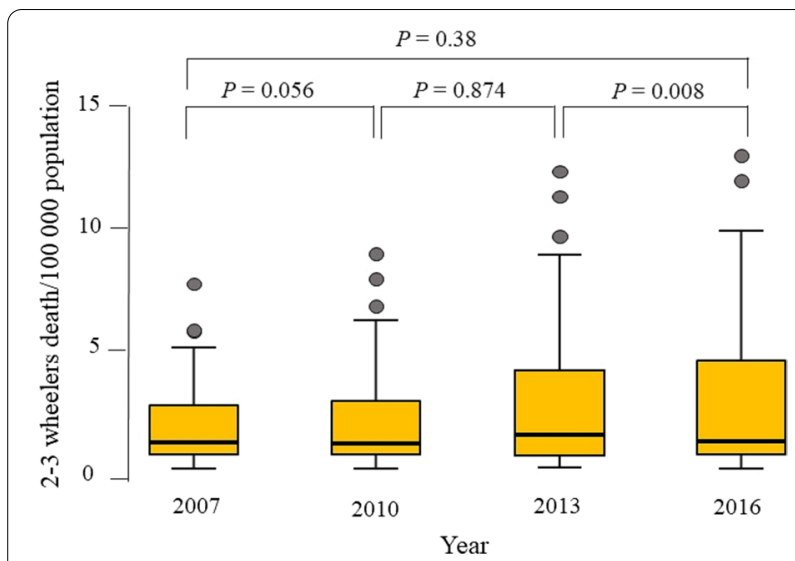

Fig. 1 Box-and-whiskers plot of motorized 2-3 wheelers death rate per 100,000 population of years 2007-2016. The box resembles the 25th percentile and the 75th percentile Interquartile Range (IQR), while the line within the box resembles the median. Black circles represent the outliers. $p$-value $=$ Friedman test for comparison of more than two dependent groups and Wilcoxon signed-rank test for comparison of two dependent groups

countries increased from $3.01 / 100,000$ population to $7.60 / 100,000$ population over the studied decade (a relative ratio of 2.52). Furthermore, there was a statistically significant increase in the mortality rate in the middle-income countries over time $(p<0.0001$, Friedman test, Fig. 2B). The mean death rate in the middle-income countries increased from 2.65/100,000 population to $3.86 / 100,000$ population over the studied decade (a relative ratio of 1.46). The increase was significant between years 2007 and $2010(p=0.001$, Wilcoxon signed-rank test). However, there was a significant drop between 2013 and $2016(p=0.003$, Wilcoxon signed-rank test). There was a significant decrease in death rate in the high-income countries over time ( $p<0.0001$, Friedman est, Fig. $2 \mathrm{C})$. The mean death rate in the high-income countries decreased from $1.92 / 100,000$ population to $1.38 / 100,000$ population over the studied decade (a relative ratio of 0.72 ).

Table 2 shows the correlations between $2-3$ wheelers per person ratio, helmet usage, and GNI, with death rate (Table 2). All these correlations were highly significant within 2007, 2010, 2013, and 2016 (Figs. 3, 4, 5). The post hoc comparisons between low-income, middle-income, and high-income countries confirmed these correlations. There was a highly significant difference in the death rate, 2-3 wheelers per person ratio, and percentage of helmet-wearing rate between these countries. Death rate decreased, 2-3 wheelers per person ratio increased, while helmet usage increased with increased income (Fig. 6).

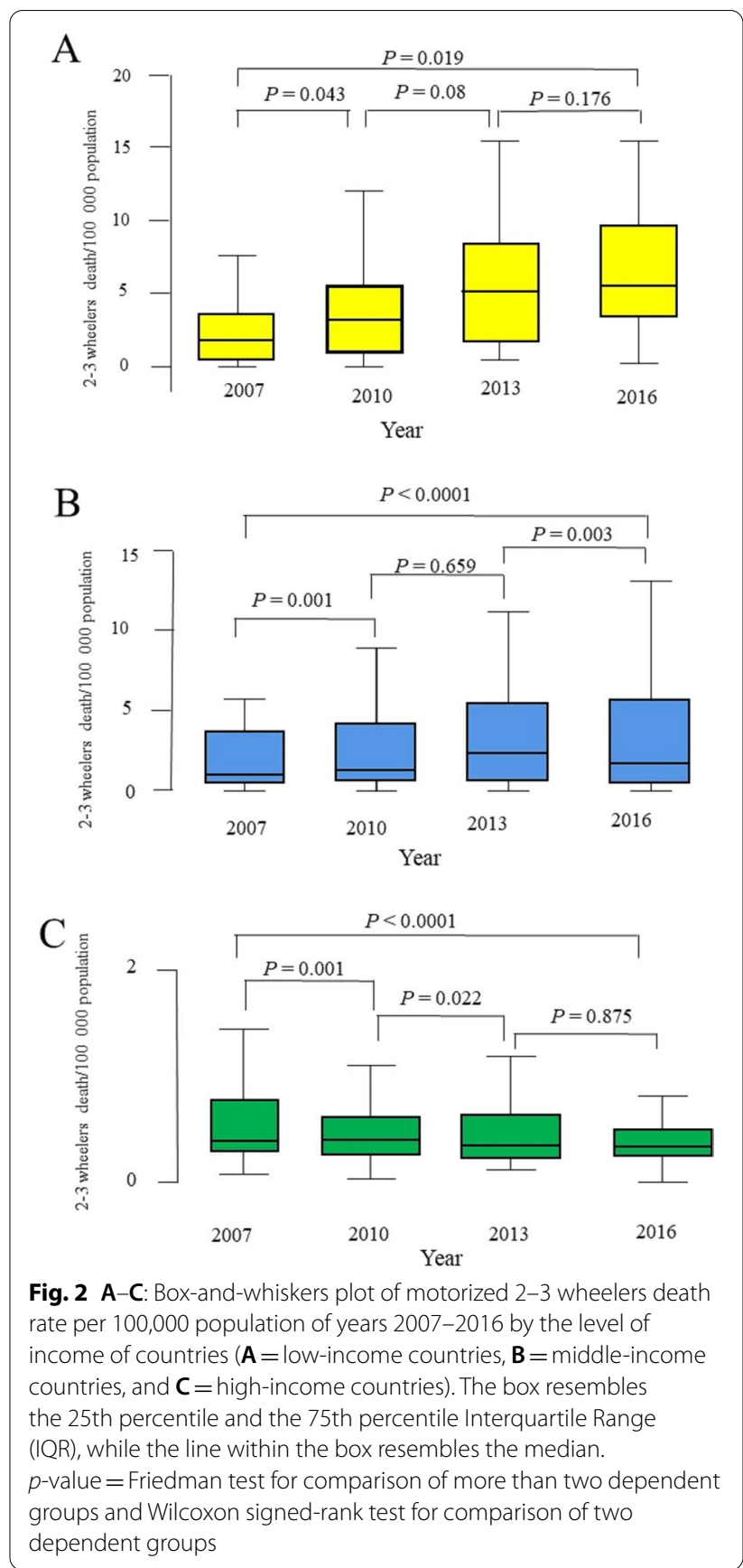

\section{Discussion}

Our study has shown that there was no significant reduction in the global motorized 2-3 wheelers death rates over the studied period which has even increased by a relative ratio of 1.36 . The UN target was not met. The death rate increased because of the increase in the motorized 2-3 wheelers and was reduced by helmet compliance and wealth. Nevertheless, there was a significant difference in the death rates between the 
Table 2 Spearman rank correlations between the significant factors that affected motorized 2-3 wheelers death rate globally over 2007-2016

\begin{tabular}{|c|c|c|c|c|c|c|}
\hline \multirow[t]{2}{*}{ Variable } & \multicolumn{2}{|c|}{ 2-3 Wheelers per person ratio } & \multicolumn{2}{|c|}{$\begin{array}{l}\text { Percentage of helmet wearing } \\
\text { rate }\end{array}$} & \multicolumn{2}{|c|}{ GNI per capita } \\
\hline & rho & $p$-value & rho & $p$-value & rho & $p$-value \\
\hline \multicolumn{7}{|l|}{ Year 2007} \\
\hline Motorcycle 2-to-3 wheelers death rate & 0.408 & $p<0.0001$ & -0.342 & $p=0.019$ & -0.048 & $p=0.610$ \\
\hline GNI & 0.494 & $p<0.0001$ & 0.390 & $p=0.002$ & - & \\
\hline \multicolumn{7}{|l|}{ Year 2010} \\
\hline Motorcycle 2-to-3 wheelers death rate & 0.35 & $p<0.0001$ & -0.389 & $p=0.003$ & -0.263 & $p=0.004$ \\
\hline GNI & 0.443 & $p<0.0001$ & 0.538 & $p<0.0001$ & - & \\
\hline \multicolumn{7}{|l|}{ Year 2013} \\
\hline Motorcycle 2-to-3 wheelers death rate & 0.382 & $p<0.0001$ & -0.422 & $p=0.001$ & -0.366 & $p<0.0001$ \\
\hline GNI & 0.420 & $p<0.0001$ & 0.669 & $p<0.0001$ & - & \\
\hline \multicolumn{7}{|l|}{ Year 2016} \\
\hline Motorcycle 2-to-3 wheelers death rate & 0.324 & $p=0.001$ & -0.661 & $p<0.0001$ & -0.312 & $p<0.0001$ \\
\hline GNI & 0.294 & $p<0.0001$ & 0.732 & $p<0.0001$ & - & \\
\hline
\end{tabular}

GNI, Gross National Income/capita (US dollars)

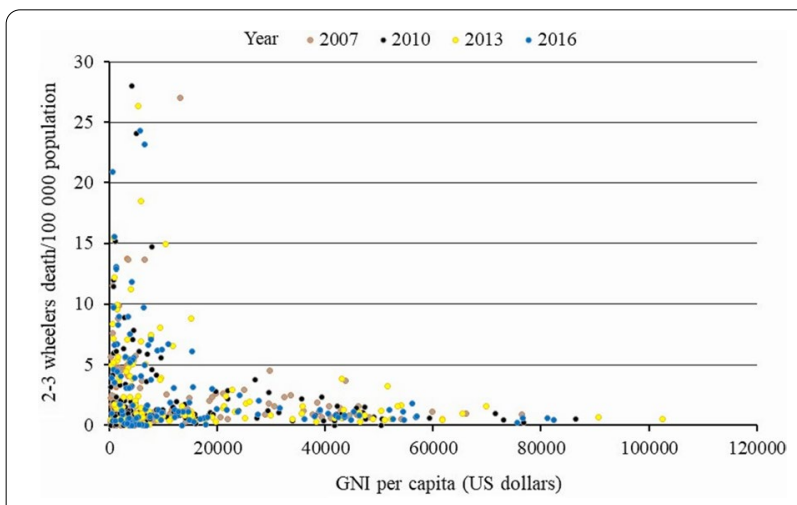

Fig. 3 Correlation (scatter plot) between motorized 2-3 wheelers death rate per 100,000 population and GNI per capita in US dollars within each years of 2007, 2010, 2013, and 2016

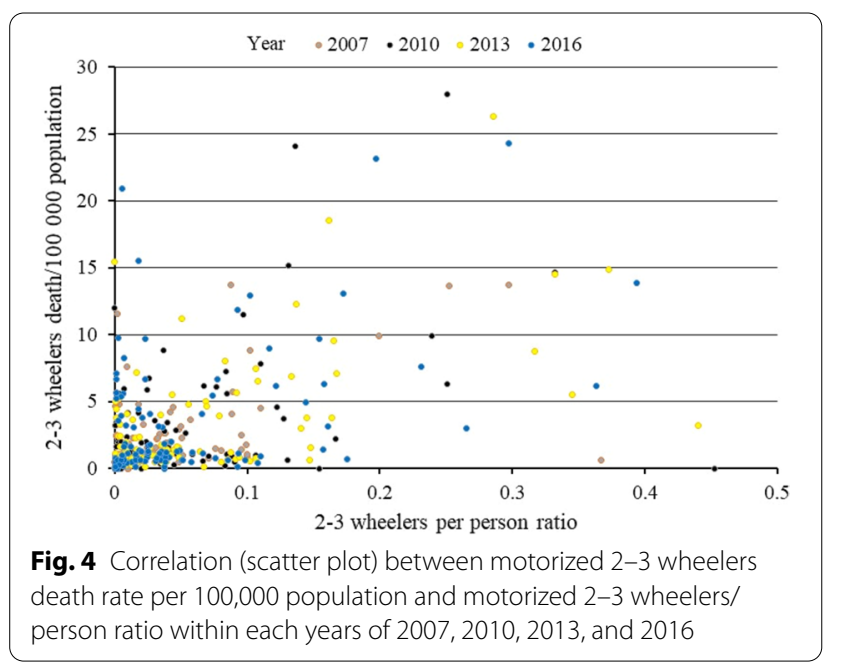

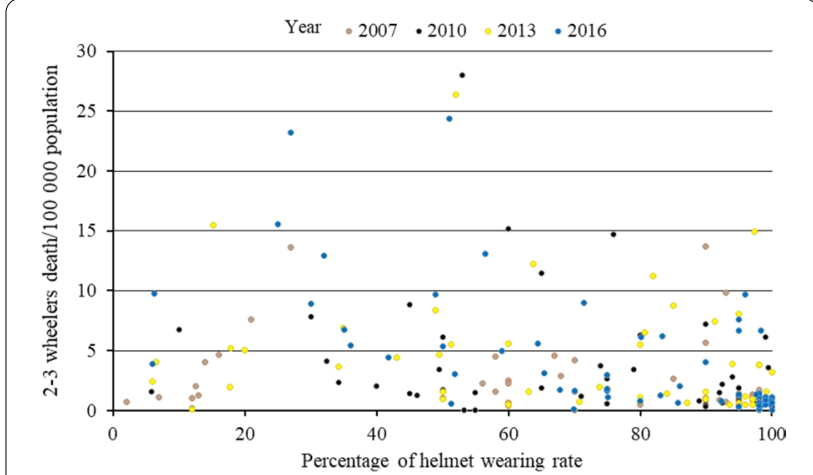

Fig. 5 Correlation (scatter plot) between motorized 2-3 wheelers death rate per 100,000 population and percentage of helmet wearing rate within each years of 2007, 2010, 2013, and 2016

three levels of income of countries with a relative ratio increase of 2.52 in the low-income countries and 1.46 in the middle-income countries, while it decreased by relative ratio of 0.72 in the high-income countries. These differences in the direction of change between the three levels explain why there was no overall global significant difference in the death rates when combined together. Other studies showed that the UN target was not met [16-18] and even suggested that mortality from motorized 2-3 wheelers would even increase globally by $11 \%$ over the coming 10 years [19].

The increased death rates were related to the increased motorized 2-3 wheelers in our study which was supported by others $[14,20,21]$. The use of motorized 2-3 wheelers increase the chances of getting a 

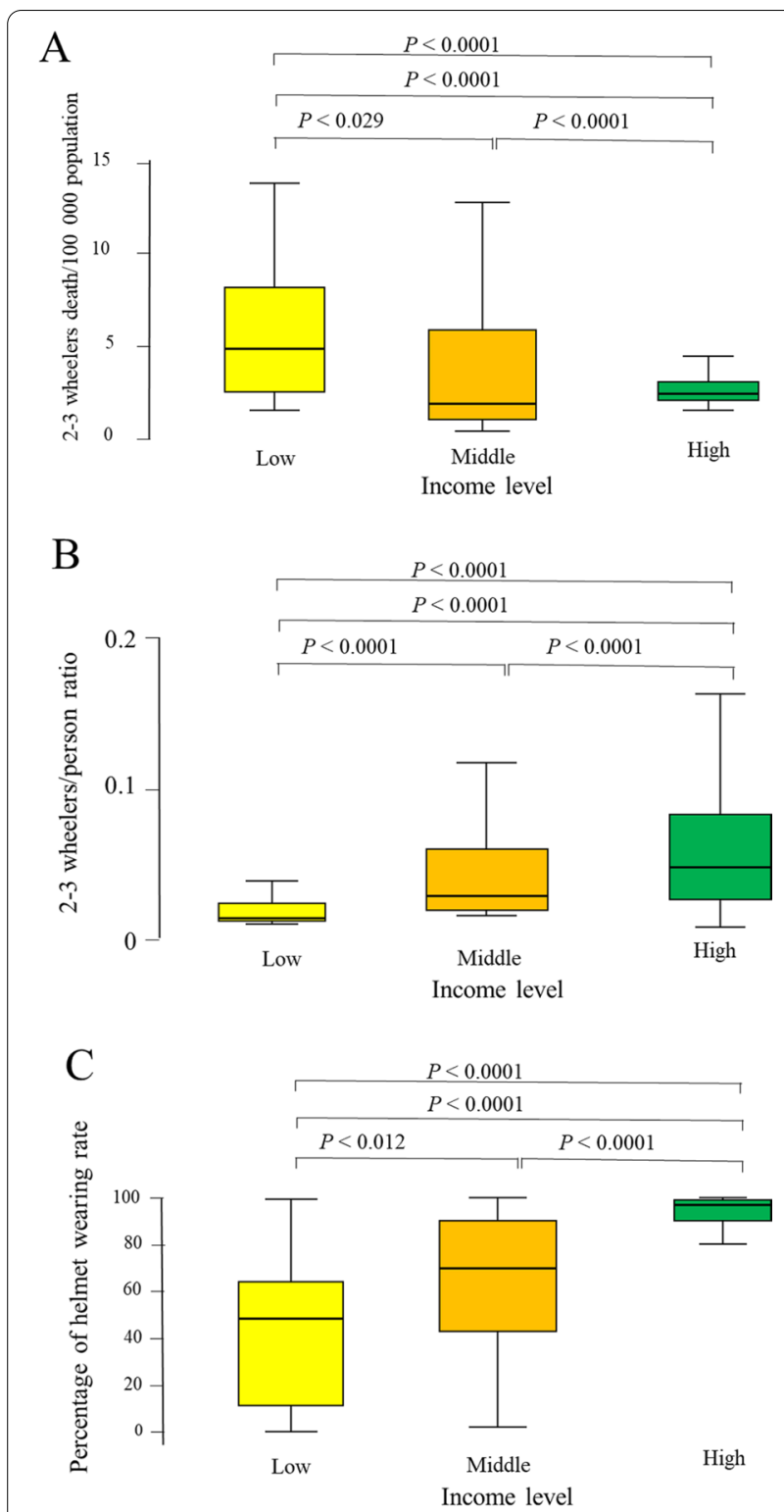

Fig. 6 Box-and-whiskers plot of motorized $2-3$ wheelers death rate per 100,000 population (A), motorized 2-3 wheelers/person ratio (B), and percentage of helmet wearing rate $(\mathbf{C})$ of years $2007-2016$ by the level of income of countries. The box resembles the 25th percentile and the 75th percentile Interquartile Range (IQR), while the line within the box resembles the median. $p$-value $=$ Mann-Whitney $U$ test for comparison of two independent groups and Kruskal-Wallis for comparison of more than two independent groups

job in poor countries. Understandably, their increased number and travel time on unsafe roads would increase the RTCs [4, 22-24]. This would be even worse if safety rules were not followed like using helmets. Helmet compliance significantly reduced the death rate of the 2-3 wheeler drivers and riders in our study. Helmets reduce the impact of head injuries which have high mortality in the 2-3-wheeler-related injuries $[8,14]$. Low GCS, indicating severe head injury, is one of the most important factors predicting mortality in RTCs [25-27].

The increased GNI reduced the overall mortality overtime in our study. Overall mortality depends on multiple factors that are correlated to each other. Finding a significance single univariate correlation with mortality is not enough to indicate that it is a predictor of mortality because it can be a confounder of another factor. Although the GNI significantly increased the number of 2-3 wheelers, it was highly correlated with an increase in helmet use in the population within each studied year. It is also possible that motorcycle drivers in high-income countries respect the speed limits and follow traffic regulations more strictly which reduces collision and death rates. Nevertheless, the mixed linear model is a strong model which depends on the slope of change within each country, can compensate for missing data, and will consider all these interactions to properly define predictors of mortality. Several previous studies showed that the increase in motorized 2-3 wheeler per person ratio is associated with initial rise of GNI. This ratio declines later on when the GNI increases more. Cars will be preferred at this stage because they are safer and more comfortable $[6,21,28-30]$. The increased GNI is also related to the effective implementation of road safety regulations (including helmet law), and improvement in medical care $[28,31]$.

\section{Limitation of the study}

Our study has certain limitations. First, our analysis depended on the WHO reports. The availability and accuracy of this data can be affected by the political agenda and the health informatics infrastructure. The World Bank highlighted a profound difference between government-reported road deaths and WHO-estimated road deaths, with under-reporting of $84 \%$ in the lowincome countries, $51 \%$ in middle-income countries, and $11 \%$ in high-income countries, [5]. We have used the estimated death rates of the WHO reports as it is more accurate. Nevertheless, this carries the risk of theoretical assumptions and modelling. Second, some important factors related to road deaths are not included in the analysis like the driver behavior, age, gender, drug/alcohol use, educational level, riding experience, and using visibility aids [8,32]. Our study is based on a country level and not on individual levels. Factors that apply to a particular person are difficult to quantify on a country level. Third, publishing WHO reports takes up to 3 years. The report for the recent 3 years has not yet been published and is not included in our current analysis. This is most properly related to the COVID-19 pandemic where more 
WHO resources were used to address the pandemic challenges. We are awaiting this global report as it may highlight the impact of COVID-19 pandemic on the RTC safety $[26,33]$. Forth, the GNI is a single collective factor with varying effects at different stages of the economic development. Although GNI in general was associated with the reduced motorized 2-3 wheelers deaths in our study, the rise of GNI at early stages would increase motorized 2-3 wheeler per person ratio while the law enforcement of safety regulations usually comes after the initial increase of mortality. Finally, data on other safety devices that can reduce motorcycle-related deaths like the Anti-Lock Brake Systems which may enable the driver to stop within a short distance $[34,35]$ were missing. We were limited by the available data in the WHO reports, and these data were not available.

\section{Conclusions}

Global mortality of motorized $2-3$ wheelers has increased by a relative ratio of 1.36 over a recent decade. The UN target of reducing death was not met. The increase was related to the increase in motorized 2-3 wheelers per person ratio and economic inequiety which has to be addressed globally. The economic global gap significantly impacts the mortality rates of motorized 2-3 wheelers.

\begin{abstract}
Abbreviations
Cl: Confidence interval; GNI: Gross national income; LMICs: Low- and middleincome countries; LL: Lower limit; MIC: Middle-income countries; MLM: Mixed linear model; RTC: Road traffic collision; SE: Standard error; SPSS: Statistical package for the social sciences; UL: Upper limit; UN: United Nations; US: United States; USA: United States of America; WHO: World Health Organization.
\end{abstract}

\section{Acknowledgements}

None

\section{Authors' contributions}

YJY, MG, and FAZ conceived and designed the experiments. YJY retrieved and coded the data. YJY and FAZ analyzed the data. YJY wrote the paper. FAZ critically edited the paper. YJY, MG, and FAZ critically read the paper. All authors read and approved the final manuscript.

\section{Funding}

There was no funding for this research study.

\section{Availability of data and materials}

Original data are published by the $\mathrm{WHO}$ and available on the website references $[1,9,10,13]$.

\section{Declarations}

Ethics approval and consent to participate

This is public published data of the $\mathrm{WHO}$, which is exempt from the approval of the human research ethics committee.

\section{Consent for publication}

Not applicable.

\section{Competing interests}

The authors declare that they have no competing interests.

\section{Author details}

${ }^{1}$ Institute of Public Health, College of Medicine and Health Sciences, UAE University, Al-Ain, United Arab Emirates. ${ }^{2}$ Department of Environmental Health and Behavioral Sciences, School of Public Health, College of Health Sciences, Mekelle University, Mekelle, Ethiopia. ${ }^{3}$ Department of Public Health and Preventive Medicine, Second Faculty of Medicine, Charles University, Prague, Czech Republic. ${ }^{4}$ Department of Surgery, College of Medicine and Health Sciences, UAE University, Al-Ain, United Arab Emirates.

Received: 25 November 2021 Accepted: 20 January 2022

Published online: 26 January 2022

\section{References}

1. World Health Organization. The Global status report on road safety. Vol. 2, Geneva. 2018. https://www.who.int/violence_injury_prevention/road_ safety_status/2018/en/. Accessed 27 Oct 2021.

2. Peden M. Saving lives through vehicle safety. Lancet Glob Heal. 2020;8:e746-7

3. World Health Organization. Powered two- and three-wheeler safety: a road safety manual for decision-makers and practitioners. 2017. https:// apps.who.int/iris/rest/bitstreams/1081388/retrieve. Accessed 27 Oct 2021

4. Kumar A. Understanding the emerging role of motorcycles in African cities. Sub-Saharan Africa Transp Policy. 2011. https://openknowledge.world bank.org/bitstream/handle/10986/17804/669410NWPODP130IC00R ole0Motorcycles.pdf;sequence $=1$. Accessed 27 Oct 2021 .

5. World Bank. Guide for road safety opportunities and challenges: low- and middle-income country profiles. Washington, DC. 2020. https://www. ssatp.org/sites/ssatp/files/publication/Guide-for-Road-Safety-Oppor tunities-and-Challenges-Low-and-Middle-Income-Country-Profiles.pdf. Accessed 07 Nov 2021.

6. Law TH, Hamid H, Goh CN. The motorcycle to passenger car ownership ratio and economic growth: a cross-country analysis. J Transp Geogr. 2015:46:122-8.

7. National Highway Traffic Safety Administration. Traffic safety facts 2016 (DOT HS 812 554). 2018. https://crashstats.nhtsa.dot.gov/Api/Public/ ViewPublication/812492. Accessed 05 Nov 2021.

8. Lin MR, Kraus JF. A review of risk factors and patterns of motorcycle injuries. Accid Anal Prev. 2009;41:710-22.

9. World Health Organization. Global status report on road safety. Vol. 15, Geneva. 2015. https://www.afro.who.int/sites/default/files/2017-06/ 9789241565066_eng.pdf. Accessed 27 Oct 2021.

10. World Health Organization. Global status report on road safety: Supporting a decade of action. Vol. 19, Geneva. 2013. http://www.who.int/viole nce_injury_prevention/road_safety_status/2013/en/. Accessed 27 Oct 2021.

11. United Nations. Global plan for the Decade of Action for Road Safety 2011-2020. Geneva:WHO. 2010. p. 25. http://scholar.google.com/schol ar?hl=en\&btnG=Search\&q=intitle:Global+Plan+for+the+Decade+ of+Action+for+Road+Safety+2011-2020\#0. Accessed 28 Oct 2021.

12. James SL, Lucchesi LR, Bisignano C, Castle CD, Dingels ZV, Fox JT, et al. Morbidity and mortality from road injuries: results from the Global Burden of Disease Study. Inj Prev. 2017;2019:1-11.

13. World Health Organization. Global status report on road safety: time for action. Geneva. 2009. http://apps.who.int/iris/bitstream/handle/10665/ 44122/9789241563840_eng.pdf;jsessionid=80D4774FE6C0CA366601 0581CD4B9C1F? sequence $=1$. Accessed 27 Oct 2021.

14. Abbas AK, Hefny AF, Abu-Zidan FM. Does wearing helmets reduce motorcycle-related death? A global evaluation. Accid Anal Prev. 2012;49:249-52.

15. InfoPlease. Area and population of countries. https://www.infoplease $\mathrm{com} /$ world/population-statistics/area-and-population-countries. Accessed 15 Oct 2021.

16. Bhalla K, Mohan D, O'Neill B. How much would low- and middle-income countries benefit from addressing the key risk factors of road traffic injuries? Int J Inj Control Saf Promot. 2020;27:83-90. 
17. Peden MM, Puvanachandra P. Looking back on 10 years of global road safety. Int Health. 2019;11:327-30.

18. Swedish Transport Administration. Saving lives beyond 2020: the next steps. In: Recommendations of the academic expert group for the 3 rd global ministerial conference on road safety. 2019. https://www.roads afetysweden.com/contentassets/c65bb9192abb44d5b26b633e70e0be 2c/200113_final-report-single.pdf. Accessed 29 Oct 2021.

19. Inada H, Li Q, Bachani A, Hyder AA. Forecasting global road traffic injury mortality. Inj Prev. 2019;26:1-5.

20. Pal C, Hirayama S, Narahari S, Jeyabharath M, Prakash G, Kulothungan V. An insight of World Health Organization (WHO) accident database by cluster analysis with self-organizing map (SOM). Traffic Inj Prev. 2018:19:S15-20.

21. Bastos SQA, Gama F, de Paula AT, Milosz M. Is there a relationship between the use of motorcycles and the level of development of countries? Bull Geogr Socio-Econ Ser. 2020;50:43-53.

22. Karema FM, Irandu EM, Moronge JM. The role of commercial motorcycles in alleviating poverty in rural areas: a case study of Laikipia East SubCounty. Kenya World Rev Intermodal Transp Res. 2017;6:155-76.

23. Ali M, Saeed MMS, Ali MM, Haidar N. Determinants of helmet use behaviour among employed motorcycle riders in Yazd, Iran based on theory of planned behaviour. Injury. 2011;42:864-9.

24. Umaru IG. Commercial motorcycle activity, value creation and the environment in the developing world: the case of Nasarawa State, Nigeria. Int J Soc Sci Res. 2013;1:122.

25. Eid HO, Barss P, Adam SH, Torab FC, Lunsjo K, Grivna M, Abu-Zidan FM. Factors affecting anatomical region of injury, severity, and mortality for road trauma in a high-income developing country: lessons for prevention. Injury. 2009;40:703-7.

26. Yasin YJ, Alao DO, Grivna M, Abu-Zidan FM. Impact of the COVID-19 Pandemic on road traffic collision injury patterns and severity in Al-Ain City, United Arab Emirates. World J Emerg Surg. 2021;16:57.

27. Al-Kuwaiti A, Hefny AF, Bellou A, Eid HO, Abu-Zidan FM. Epidemiology of head injury in the United Arab Emirates. Ulus Travma Acil Cerrahi Derg. 2012;18:213-8.

28. Law TH, Noland RB, Evans AW. Factors associated with the relationship between motorcycle deaths and economic growth. Accid Anal Prev. 2009:41:234-40

29. Chu MY, Law TH, Hamid H, Law SH, Lee JC. Examining the effects of urbanization and purchasing power on the relationship between motorcycle ownership and economic development: a panel data. Int J Transp Sci Technol. 2021. https://doi.org/10.1016/j.jitst.2020.12.004.

30. Pongthanaisawan J, Sorapipatana C. Relationship between level of economic development and motorcycle and car ownerships and their impacts on fuel consumption and greenhouse gas emission in Thailand. Renew Sustain Energy Rev. 2010;14:2966-75.

31. Sirajudeen AO, Law TH, Wong SV, Jakarni FM, Ng CP. The sources of the Kuznets relationship between the road deaths to road injuries ratio and economic growth. J Safety Res. 2021;78:262-9.

32. Sumit K, Ross V, Brijs K, Wets G, Ruiter RAC. Risky motorcycle riding behaviour among young riders in Manipal. India BMC Public Health. 2021:21:1954.

33. Yasin YJ, Grivna M, Abu-Zidan FM. Global impact of COVID-19 Pandemic on road traffic collisions. World J Emerg Surg. 2021;16:51.

34. Seiniger P, Schröter K, Gail J. Perspectives for motorcycle stability control systems. Accid Anal Prev. 2012;44:74-81.

35. Mollenhauer MA, Dingus TA, Carney C, Hankey JM, Jahns S. Anti-lock brake system: an assessment of training on driver effectiveness. Accid Anal Prev. 1997;29:97-108

\section{Publisher's Note}

Springer Nature remains neutral with regard to jurisdictional claims in published maps and institutional affiliations. 